\title{
Age differences in patients presenting with acute coronary syndro- me - does age influence the severity of the disease and outcome?
}

\author{
Dario Gulin ${ }^{1,2 *}$ \\ Jozica Šikićn ${ }^{1,2}$, \\ Ana Marija Slišković ${ }^{3}$, \\ Edvard Galić1,2, \\ Jasna Čerkez Habek ${ }^{1,4}$, \\ Tea Blažević1,2 \\ 'University Hospital "Sveti \\ Duh", Zagreb, Croatia \\ 'University of Zagreb School \\ of Medicine, Zagreb, Croatia \\ ${ }^{3}$ The Croatian Institute of \\ Emergency Medicine, Zagreb, \\ Croatia \\ ${ }^{4}$ Croatian Catholic University, \\ Zagreb, Croatia
}

KEYWORDS: acute coronary syndrome, myocardial infarction, age.

CITATION: Cardiol Croat. 2018;13(1-2):30. | https://doi.org/10.15836/ccar2018.30

*ADDRESS FOR CORRESPONDENCE: Dario Gulin, Klinička bolnica „Sveti Duh", Sveti Duh 64, HR-10000 Zagreb, Croatia. / Phone: +385-91-3713-398 / E-mail: dariogulin@gmail.com

ORCID: Dario Gulin, https://orcid.org/0000-0001-8502-7816 • Jozica Šikić, https://orcid.org/0000-0003-4488-0559 Ana Marija Slišković, https://orcid.org/0000-0001-6622-7572 • Edvard Galić, https://orcid.org/0000-0002-5707-0961 Jasna Čerkez Habek, https://orcid.org/0000-0003-3177-3797 • Tea Blažević, https://orcid.org/0000-0003-3189-8661

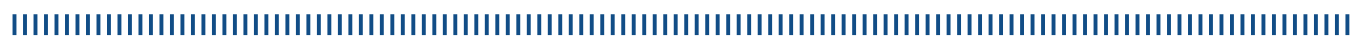

Introduction: Acute coronary syndrome (ACS) mainly occurs in patients over 50 years of age, but younger patients can also be affected. ${ }^{1,2}$

Patients and Methods: This retrospective observational study was conducted in our cardiovascular department in an eight-month period. The cutoff of 50 years was used to determine clinical characteristics and outcomes of patients younger than 50 years (YP) comparing them with older than 50 years (OP).

Results: Among the 219 patients with ACS, 26 (11.8\%) were YP. Women were affected in 11.5\% in YP and $32.1 \%$ in OP group. There were no female patients younger than 46 years. Compared to OP, YP had the lower prevalence of previous myocardial infarction (3.8\% vs. $17.1 \%$ ) and previous PCI (3.8\% vs. $11.9 \%$ ). Cerebrovascular disease was present in $5.7 \%$ and peripheral artery disease in $6.7 \%$ of OP, while in YP both were not observed. Previous cardiovascular risk factors were present in YP: smoking $65.4 \%$ vs. $29.4 \%$ in OP; arterial hypertension $57.7 \%$ vs. $75.6 \%$; diabetes $26.9 \%$ vs. $23.8 \%$; hyperlipidemia $42.3 \%$ vs. $61.6 \%$. Beta blockers were used in $19.2 \%$, ACE inhibitors in $3.8 \%$ and statins in $11.5 \%$ of YP, while $27.9 \%$, $33.6 \%$ and $24.8 \%$ in OP. Mean hospitalization stay was 5.26 days in YP (median 4 days) and 7.38 in OP (median 5 days). Culprit coronary artery was in YP RCA in 42.8\%, LAD in 28.6\% and ACx in 28.6\%, while in OP RCA in $37.7 \%$, LAD in $41.3 \%$ and ACx in $21.0 \%$. In YP, type A lesion was present in $19 \%$, type B in $42.8 \%$, type $\mathrm{C}$ in $4.8 \%$ and coronary occlusion in $33.4 \%$; while in OP $21.4 \%, 32.4 \%, 13.1 \%$ and $33.1 \%$. YP had fewer coronary segments involved (2.92 vs. 3.46). A median value of percent of luminal stenosis was $99 \%$ in both groups (mean value of $91 \%$ in YP and $94.7 \%$ in OP). The mean number of stents implanted was higher in YP (1.46 vs. 1.17). GpIIb/IIIa inhibitor was used in $30.7 \%$ of YP vs. $15 \%$ of OP.

Discussion and Conclusion: Patients younger than 50 years present smaller percentage of ACS patients. Our study showed no differences between the percentage of complete vessel occlusion in YP and OP. Among cardiovascular risk factors, greatest difference was seen in smoking. YP had less documented arterial hypertension, hyperlipidemia, and rate of previous drug use. RCA and ACx were more frequent culprit in YP and LAD in OP. YP had less coronary segments affected but higher rates of implanted stents and more need for antiplatelet GpIIb/IIIa therapy.

LITERATURE IIIIIIIIIIIIIIIIIIIIIIIIIIIIIIIIIIIIIIIIIIIIIIIIIIIIIIIIIIIIIIIIIIIIIIIIIIIIIIIIIIIIIIIIIIIIIIIIIII

1. Ricci B, Cenko E, Vasiljevic Z, Stankovic G, Kedev S, Kalpak O, et al. Acute Coronary Syndrome: The Risk to Young Women. J Am Heart Assoc. 2017 Dec 22;6(12). pii: e007519. https://doi.org/10.1161/JAHA.117.007519

2. Vasiljevic-Pokrajcic Z, Mickovski N, Davidovic G, Asanin M, Stefanovic B, Krljanac G, et al. Sex and age differences and outcomes in acute coronary syndromes. Int J Cardiol. 2016 Aug;217 Suppl:S27-31. https://doi.org/10.1016/j.ijcard.2016.06.217 